\title{
(C) OPEN ACCESS \\ Diffuse lung disease of infancy: a pattern-based, algorithmic approach to histological diagnosis
}

\author{
Jane E Armes, ${ }^{1}$ William Mifsud, ${ }^{2}$ Michael Ashworth ${ }^{2}$
}

${ }^{1}$ Department of Anatomical Pathology, Mater Health Services, South Brisbane, Queensland, Australia ${ }^{2}$ Department of

Histopathology, Great Ormond Street Hospital, London, UK

\section{Correspondence to}

Dr Michael Ashworth, Histopathology Department, Camelia Botnar Laboratories, Great Ormond Street Hospital for Children NHS Trust, Great Ormond Street, London WC1N 3JH, UK;

Michael.Ashworth@gosh.nhs. uk

Received 19 September 2014 Accepted 25 October 2014 Published Online First 4 December 2014

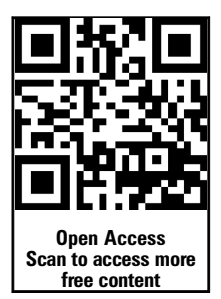

\section{ABSTRACT}

Diffuse lung disease (DLD) of infancy has multiple aetiologies and the spectrum of disease is substantially different from that seen in older children and adults. In many cases, a specific diagnosis renders a dire prognosis for the infant, with profound management implications. Two recently published series of DLD of infancy, collated from the archives of specialist centres, indicate that the majority of their cases were referred, implying that the majority of biopsies taken for DLD of infancy are first received by less experienced pathologists. The current literature describing DLD of infancy takes a predominantly aetiological approach to classification. We present an algorithmic, histological, pattern-based approach to diagnosis of DLD of infancy, which, with the aid of appropriate multidisciplinary input, including clinical and radiological expertise and ancillary diagnostic studies, may lead to an accurate and useful interim report, with timely exclusion of inappropriate diagnoses. Subsequent referral to a specialist centre for confirmatory diagnosis will be dependent on the individual case and the decision of the multidisciplinary team.

\section{INTRODUCTION}

Diffuse lung disease (DLD) of infancy can be confronting to the pathologist who is not specialised in paediatric pulmonary pathology. The spectrum of disease and its aetiology is substantially different from that of adults and older children, and its pathological diagnosis invariably has a profound impact on clinical management. DLD of infancy presents with symptoms of impaired gas exchange together with diffuse infiltrates on imaging and this presentation is not specific as to the underlying cause. ${ }^{1}$ Two recently published series of DLD of infancy, collated from the archives of specialist centres, indicate that the majority of their cases were referred, implying that the majority of biopsies taken for DLD of infancy are first received by pathologists with lesser expertise and experience in these relatively rare conditions. ${ }^{2}{ }^{3}$ In all cases, a multidisciplinary team approach to diagnosis is essential, with appropriate clinical and radiological input. Referral of biopsies to a specialist centre may be appropriate in many cases. However, the current report proposes a pattern-based approach to diagnosis of the infant lung biopsy which can be useful for the non-specialist. While a definitive diagnosis may only be reached following expert consultation, it is hoped that the approach outlined herein may lead to an accurate and useful interim report, with timely exclusion of inappropriate diagnoses.

\section{Diagnostic scope}

The approach is aimed at diagnosis of DLD in neonates as well as children $<2$ years of age and is based on the classification proposed by the chILDRN (chILD Research Network). ${ }^{4}$ This classification divides DLD of infancy into those conditions that are more prevalent in infancy and other conditions that can occur at any age, such as disorders due to systemic disease (eg, collagen vascular disorders), infectious and other environmental agents, hypersensitivities and disorders of the immunocompromised host (box 1). ${ }^{2}{ }^{4}$ The approach described will deal primarily with diagnosis of DLDs that are more specific to infancy, previously reported to constitute $60 \%$ of lung biopsies taken at $<2$ years of age for symptoms of DLD. ${ }^{4}$ Lung pathology, which is not specific to infancy and lung pathology in the immunocompromised host, will not be addressed, and such disease has been recently comprehensibly described ${ }^{5}$ and reviewed. ${ }^{2-4}$ When using the approach described herein, the pathologist should be aware that the biopsy may exhibit a combination of infant-specific and non-specific disease (eg, alveolar growth abnormality (AGA) combined with infection).

Pulmonary hypertensive disease and its possible aetiology have been included in the diagnostic algorithm since histological changes of pulmonary hypertension are commonly encountered as a secondary event in DLD of infancy and clinically, pulmonary hypertension may be a prominent feature of DLD of infancy. For completion, aetiological causes of pulmonary hypertension other than DLD of infancy have also been included, particularly because these non-pulmonary causes have to be considered in any condition when lung biopsy is taken in the setting of pulmonary hypertension.

\section{Normal anatomy}

Diagnosis should not be attempted without a working knowledge of the normal anatomy of the neonatal lung. Gas exchange takes place in the acinus, that is, the functional unit of the lung, comprising the respiratory bronchiole, alveolar ducts and alveoli (figure 1). Several acini are present within a lung lobule, with lung lobules separated by inter-lobular septa. The walls of the alveoli are necessarily thin, with the air spaces primarily lined by squamoid type I pneumocytes. Type II pneumocytes are cuboidal and are not obvious in normal lung. They produce surfactant, are the progenitors of type I pneumocytes and hence proliferate to colonise the alveolar walls following type I pneumocyte damage.

The anatomy of the vasculature of the lungs is unique. It is important to note that the pulmonary venous network does not run with the pulmonary arteries and also that the lung has a dual arterial blood supply. It is essential to accurately identify 
Box 1 Classification of diffuse lung disease in children under 2 years of age (modified from Deutsch et $a I^{4}$ and Langston and Dishop ${ }^{2}$ )

Disorders more prevalent in infancy:

Diffuse developmental disorders

Acinar dysplasia

Congenital alveolar dysplasia

Alveolar capillary dysplasia with misalignment of pulmonary veins

Growth abnormalities

Prenatal conditions: secondary pulmonary hypoplasia

Postnatal conditions: chronic neonatal lung disease

Prematurity related

Term infants with chronic neonatal lung disease

Associated with chromosomal disorders

Associated with congenital heart disease

Specific conditions of undefined aetiology

Neuroendocrine cell hyperplasia of infancy

Pulmonary interstitial glycogenosis

Surfactant dysfunction disorders

Surfactant protein B genetic mutations

Surfactant protein $C$ genetic mutations

ABCA3 genetic mutations

Histology consistent with surfactant protein dysfunction

with no genetic confirmation

Disorders not specific to infancy

Previously normal hosts

Infection/postinfectious disease

Related to environmental agents

Hypersensitivity pneumonitis

Toxic inhalation

Aspiration syndromes

Eosinophilic pneumonia

Acute interstitial pneumonia

Non-specific interstitial pneumonia

Idiopathic pulmonary haemosiderosis

Others

Disorders of the immunocompromised host

Opportunistic infections

Disorders related to therapy

Disorders related to transplantation and graft rejection

Disorders relating to systemic disease

Immune-mediated disorders

Storage disease

Sarcoidosis

Langerhans cell histiocytosis

Malignant infiltrates

Other

Disorders masquerading as interstitial lung disease

Arterial hypertensive vasculopathy

Congestive changes relating to cardiac dysfunction

Veno-occlusive disease

Lymphatic disorders

Pulmonary oedema

Unclassifiable

Includes end-stage lung disease, non-diagnostic, inadequate biopsies

the different components of the vasculature within the biopsy in order to prevent mistaken diagnosis of vascular developmental abnormality or pulmonary hypertensive disease, or conversely, to prevent a missed diagnosis of these conditions. The pulmonary arteries carry deoxygenated blood from the right ventricle and accompany the bronchi and bronchioles down to the level of the respiratory bronchioles, progressing from elastic to muscular arteries. The latter have a characteristic, well-formed internal and external elastic lamina, demonstrable with elastic stains, such as Elastic Van Gieson (EVG, figure 2) and should be similar in calibre to the accompanying bronchiole. The walls of the muscular pulmonary arteries undergo modification following birth due to the decrease in pulmonary arterial pressure. During the first few weeks of life, the media is relatively thick and the lumen narrow. However, by approximately 1 year of age, the muscular pulmonary arteries are thin-walled compared with those of the systemic circulation due to the reduced pressure within the pulmonary circulation. The muscular pulmonary arteries lead to arterioles that diverge from the respiratory bronchioles and travel within the intra-acinar connective tissue and thence to alveolar capillaries. The larger arterioles are muscular at birth, but lose this muscularisation with postnatal life. ${ }^{6}$ The capillary network is closely opposed to the type I pneumocytes in the alveolar wall, separated only by fused basement membranes, facilitating gas exchange.

As noted above, the pulmonary venous network does not run with the pulmonary arteries in the bronchovascular bundles, but travels to the main pulmonary veins via venules and small veins within the inter-lobular septa. These vessels are thin-walled and have a single elastic lamina, but can be difficult to distinguish from arterioles, particularly in diseased states, unless the position of the vessel is noted. Pulmonary lymphatics are present within the bronchovascular bundles, in the pleura and adjacent to the pulmonary veins in the inter-lobular septa.

The bronchial arteries arise from the systemic circulation (via the thoracic aorta) and distribute oxygenated blood to the bronchi and connective tissue of the lungs. The bronchial arteries travel with the connective tissue of the bronchovascular bundles and are recognisable to the level of the terminal bronchioles. These vessels are relatively small-calibre, have a relatively thick media and no external elastic lamina. Beyond the terminal bronchiole, the bronchial circulation is difficult to identify; the bronchial and pulmonary vessels anastomose and the majority of the bronchial arterial blood flow is returned via the pulmonary veins.

\section{APPROACH TO DIAGNOSIS OF DLD OF INFANCY}

A multidisciplinary approach to diagnosis of DLD of infancy is necessary, with appropriate input from clinical and imaging teams. Additionally, a pre-biopsy consultation with an expert pathologist at a specialist centre regarding possible aetiologies, appropriate sampling, biopsy technique and ancillary analyses may be appropriate. In all cases, whenever a paediatric lung biopsy is received, adequate specimen handling and processing is necessary for optimal diagnosis (see Langston $e t a l^{7}$ ).

The current literature describing DLD of infancy takes a predominantly aetiological approach to classification (box 1). However, pathological diagnosis is necessarily pattern based. DLD of infancy exhibits a limited number of primary disease patterns and can be accompanied by additional histological features due to associated diseases. We propose an algorithm using histological, pattern-based appearances, to determine the probable cause of the DLD (figure 3). This algorithmic template can be used in conjunction with the more detailed information concerning clinical presentation, appropriate ancillary studies and outcome as described in the subsequent text and table 1. 


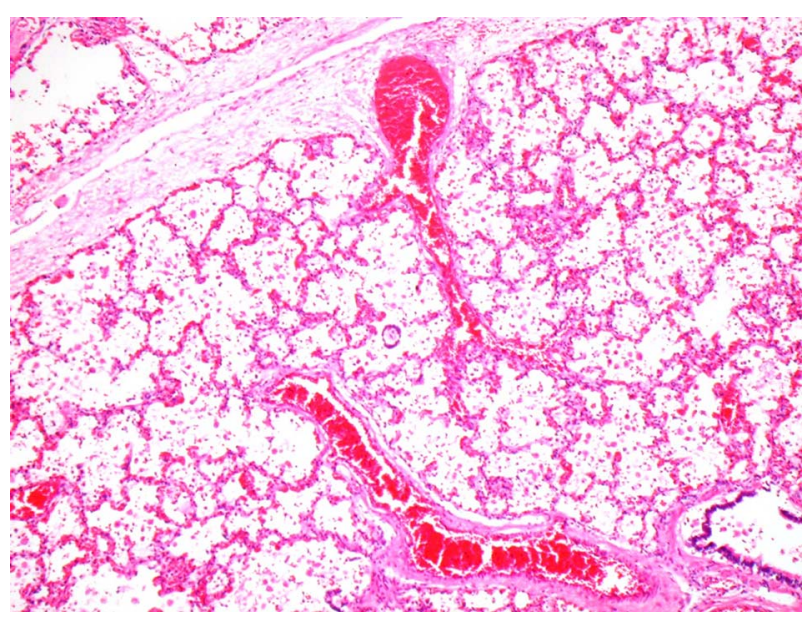

Figure 1 The functional unit of the lung: terminal bronchiole (bottom right), alveolar ducts and alveoli within a lung lobule bounded by an inter-lobular septum (top left to centre). Note the artery accompanying the bronchiole: the vein lies separately in the inter-lobular septum.

Note also how thin the alveolar septa are: they contain a single capillary. Connective tissue is largely confined to the sheath around the bronchiole and artery and to the interlobular septum.

\section{Arrested alveolar development}

Rarely, term neonates develop respiratory failure due to lung maturation arrest. The lung histology is developmentally primitive.

\section{Acinar dysplasia}

When the lung histology is reminiscent of either the pseudoglandular or early canalicular stage of fetal lung differentiation, acinar dysplasia (AD) is diagnosed (figure 4). In $\mathrm{AD}$, the airway development is limited to the bronchial and bronchiolar structures. The descriptive term 'pseudoglandular' is used since the epithelium of the distal airways is simple columnar with subnuclear glycogen vacuoles, which imparts a glandular

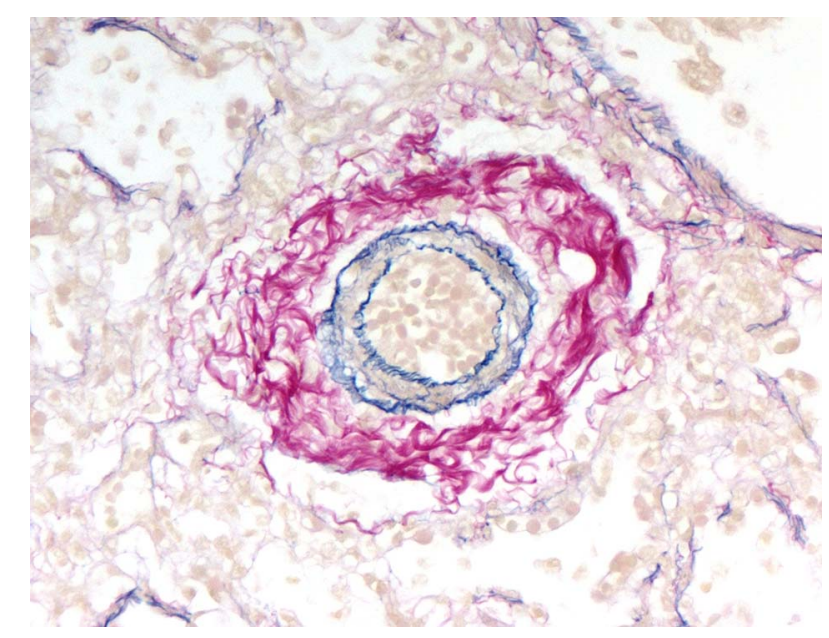

Figure 2 A muscular pulmonary artery with well-formed internal and external elastic lamina, demonstrable by elastic stains (Elastic van Gieson). The artery has a thick collagenous adventitial coat that merges with the collagen around the accompanying bronchiole seen in part at top right (the pulmonary veins have a much thinner collagenous adventitia). Note that there is a layer of elastic tissue present in the mucosa of the bronchiole. The bronchiole and artery should generally be about equal in diameter. appearance. There is abundant mesenchyme surrounding the airways resulting in lobular architecture, and the airways lie at some distance from the capillary bed. Respiration is, therefore, impossible. $\mathrm{AD}$ is exceptionally rare and has been previously classified with the congenital pulmonary airway malformations (CPAM; type 0$).{ }^{8} \mathrm{AD}$ is bilateral, and the lungs are characteristically very small (figure $4 \mathrm{~A}$ ). Infants with $\mathrm{AD}$ are refractory to ventilator support and usually die shortly after birth. For this reason, $\mathrm{AD}$ is more likely to be encountered at autopsy than biopsy.

\section{Congenital alveolar dysplasia}

Congenital alveolar dysplasia (CAD) is diagnosed when the lung development is arrested in the late canalicular or early saccular stage (figure 5). Here the low-power, lobular architecture is less pronounced, airspaces are more numerous with irregular outlines, the airspaces are lined by cuboidal epithelium and subnuclear glycogen is lost. Secondary mesenchymal crests containing capillaries are present within the airspaces, which divide them into saccules. The changes of CAD are present diffusely throughout the biopsy, and no normal lung tissue is present. This generalised growth abnormality is important to document since changes similar to CAD may be seen in other conditions, although they are then only focally present. In contrast to infants with $\mathrm{AD}$, infants with $\mathrm{CAD}$ present with respiratory failure and pulmonary hypertension in the early neonatal period and can be successfully ventilated. Hence, biopsy is more likely for this condition. ${ }^{2}$ Nonetheless, these infants are ventilator-dependent and die due to respiratory failure.

\section{Alveolar simplification (AGAs)}

Alveolar simplification is the hallmark of growth abnormalities reflecting deficient alveolarisation (AGAs). Alveolar simplification is primarily a low-power diagnosis. The main morphological feature is enlargement and simplification of the alveolar spaces, which become rounded or elongate and lack septation (figure 6). In some cases, there can be cystic changes with mild interstitial fibrosis. The alveolar spaces themselves are usually empty, and type II pneumocyte hyperplasia is not present. It is important to note that under-inflation or over-inflation with formalin can lead to changes in the alveolar outlines that can mimic lung disease due to alveolar simplification. There are two common secondary changes that can accompany alveolar simplification; one is interstitial thickening due to pulmonary interstitial glycogenosis (PIG, see the pulmonary interstitial glycogenosis section) and the other is hypertensive vascular change, the latter thought to be due to the increased vascular resistance of the reduced capillary bed. ${ }^{9}$

One study indicates that the age at biopsy for this condition varies from the first weeks of life through to 11 months. ${ }^{2}$ When the biopsy is taken early, it may be performed to exclude alveolar capillary dysplasia (ACD) since neonates with both alveolar simplification and ACD can have significant pulmonary hypertension. $^{2}$ Occasionally, these two diseases occur together. Alveolar simplification is one of the most common biopsyconfirmed causes of DLD of infancy. ${ }^{2} 3$

There are several causes of growth abnormality that manifest as AGA. The most common is prematurity, when the condition is known as chronic neonatal lung disease (CNLD). This is a milder pattern of lung disease than that which used to occur in premature neonates, who were ventilated, and which was known as hyaline membrane disease/bronchopulmonary dysplasia $(\mathrm{HMD} / \mathrm{BPD})$. $\mathrm{HMD} / \mathrm{BPD}$ is characterised by sequential severe acute lung injury with hyaline membranes followed by 

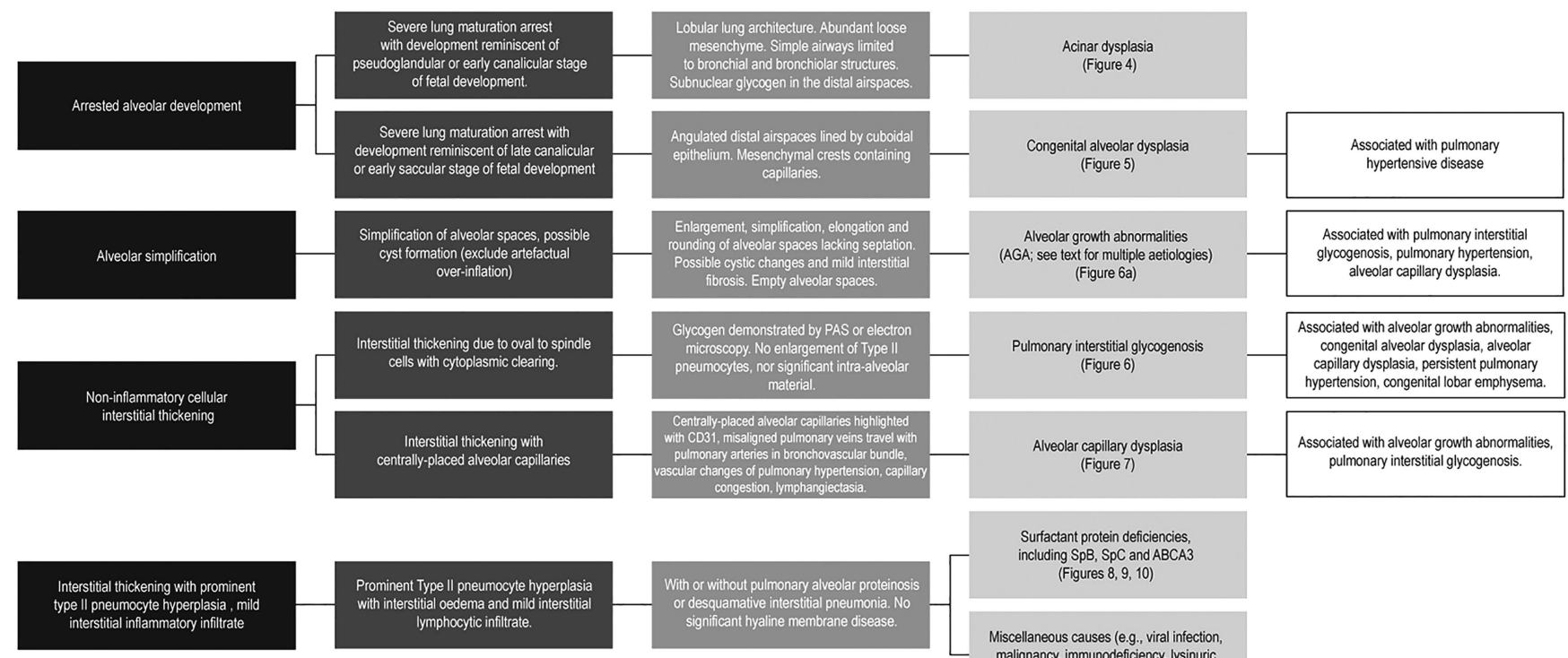

\section{Surfactant protein deficiencies,
including $\mathrm{SPB}, \mathrm{SpC}$ and $\mathrm{ABCA} 3$} (Figures $8,9,10$ )
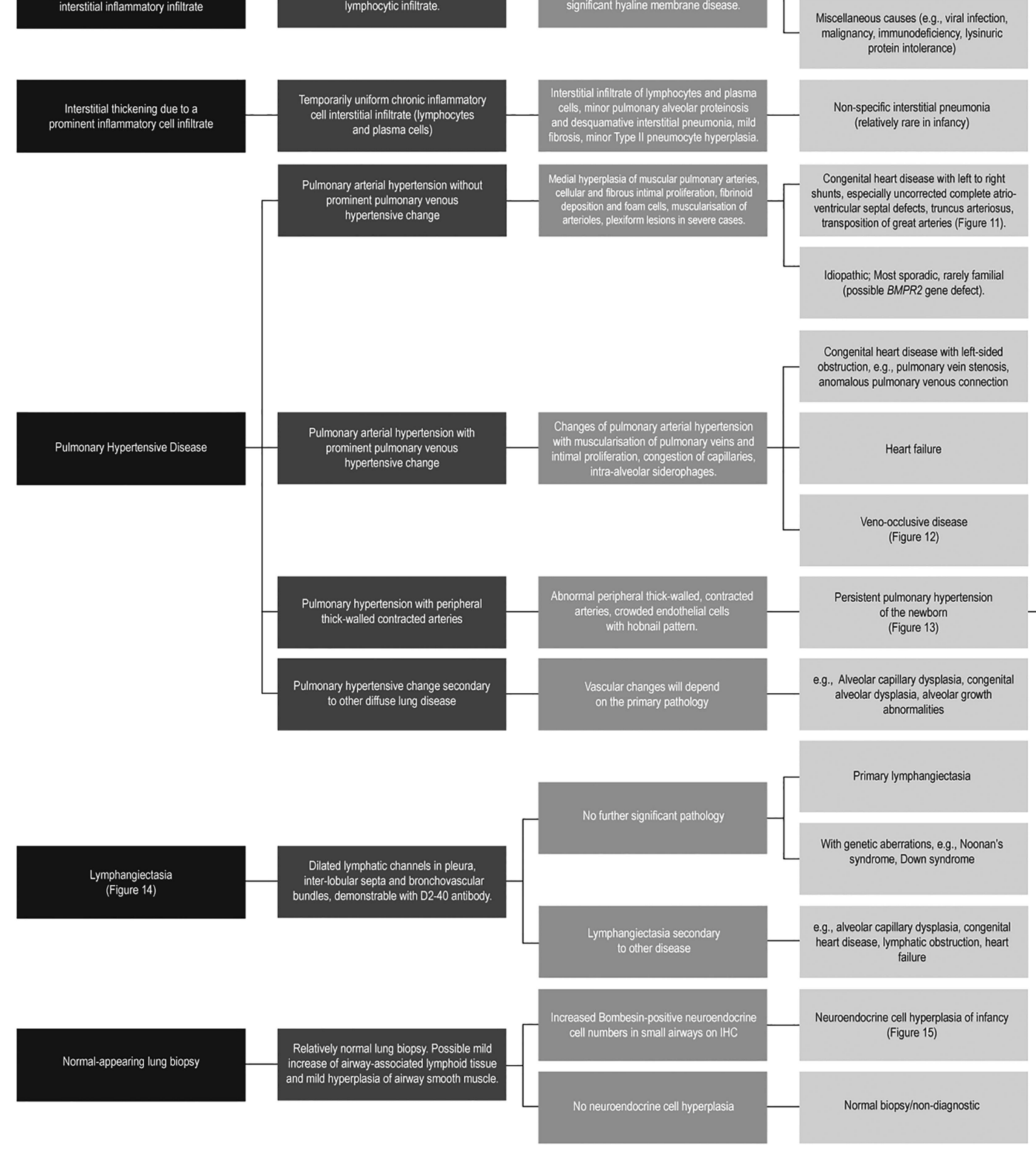

Miscellaneous causes (e.g., viral infection, malignancy, immunodeficiency, lysinuric protein intolerance)

Figure 3 An algorithmic, histological, pattern-based approach to diagnosis of diffuse lung disease of infancy. IHC, immunohistochemistry; PAS, periodic acid Schiff; SpB, surfactant protein B; SpC, surfactant protein C. 
Table 1 Age at presentation, histological patterns, ancillary studies and mortality rate of DLD specific to infancy

\begin{tabular}{|c|c|c|c|c|c|}
\hline Diagnosis & $\begin{array}{l}\text { Age at } \\
\text { presentation }\end{array}$ & Primary pattern & $\begin{array}{l}\text { Possible associated } \\
\text { conditions }\end{array}$ & Ancillary studies & Mortality rate \\
\hline \multicolumn{6}{|c|}{ Diffuse developmental disorders } \\
\hline Acinar dysplasia ${ }^{8}$ & Newborn & Delayed alveolar development & & & $100 \%$ \\
\hline Alveolar dysplasia ${ }^{2}$ & $<2$ months & Delayed alveolar development & $\begin{array}{l}\text { Pulmonary interstitial } \\
\text { glycogenosis }\end{array}$ & & $100 \%$ \\
\hline $\begin{array}{l}\text { Alveolar capillary dysplasia } \\
\text { with misalignment of } \\
\text { pulmonary veins }{ }^{2}\end{array}$ & Newborn & $\begin{array}{l}\text { Pulmonary hypertensive } \\
\text { changes } \\
\text { Interstitial thickening and } \\
\text { congestion } \\
\text { Alveolar capillary dysplasia } \\
\text { and misalignment of } \\
\text { pulmonary veins }\end{array}$ & $\begin{array}{l}\text { Pulmonary interstitial } \\
\text { glycogenosis } \\
\text { AGAs } \\
\text { Lymphangiectasia }\end{array}$ & $\begin{array}{l}\text { EVG, CD34 IHC, SMA IHC, FOXF1 } \\
\text { mutation analysis }\end{array}$ & $100 \%$ \\
\hline $\begin{array}{l}\text { Congenital pulmonary } \\
\text { lymphangiectasia }\end{array}$ & Newborn & lymphangiectasia & & EVG, D2-40 IHC & $100 \%$ \\
\hline \multicolumn{6}{|c|}{ Alveolar growth abnormalities ${ }^{4}$} \\
\hline $\begin{array}{l}\text { Pulmonary hypoplasia, } \\
\text { prematurity } \\
\text { term; no specific factors } \\
\text { Down's syndrome } \\
\text { Congenital heart disease }\end{array}$ & $0.3-22$ months & Alveolar simplification & $\begin{array}{l}\text { Pulmonary interstitial } \\
\text { glycogenosis } \\
\text { Pulmonary } \\
\text { hypertensive changes }\end{array}$ & $\begin{array}{l}\text { Broad spectrum anticytokeratin IHC } \\
\text { (eg, MNF116 antibody), EVG }\end{array}$ & $\begin{array}{l}34 \% \text { overall, } \\
\text { depending on cause } \\
\text { of AGA }\end{array}$ \\
\hline \multicolumn{6}{|l|}{ Undefined aetiology } \\
\hline $\begin{array}{l}\text { Pulmonary interstitial } \\
\text { glycogenosis }{ }^{4}\end{array}$ & $\begin{array}{l}0.3-3 \text { months } \\
\text { not }>6 \text { months }\end{array}$ & $\begin{array}{l}\text { Interstitial thickening with } \\
\text { non-inflammatory cells }\end{array}$ & $\begin{array}{l}\text { AGAs } \\
\text { Congenital alveolar } \\
\text { dysplasia } \\
\text { Alveolar capillary } \\
\text { dysplasia }\end{array}$ & PAS, electron microscopy & $0 \%$ \\
\hline $\begin{array}{l}\text { Neuroendocrine cell } \\
\text { hyperplasia of infancy }{ }^{2}\end{array}$ & 2.7-24 months & $\begin{array}{l}\text { Normal-appearing lung } \\
\text { biopsy }\end{array}$ & & Bombesin IHC & $0 \%$ \\
\hline \multicolumn{6}{|l|}{ Surfactant deficiencies } \\
\hline ABAC3 deficiency ${ }^{4}$ & $0.2-3.0$ months & $\begin{array}{l}\text { Interstitial thickening with } \\
\text { prominent type II } \\
\text { pneumocytes, PAP, DIP }\end{array}$ & CPI, NSIP & $\begin{array}{l}\text { Broad spectrum anticytokeratin IHC } \\
\text { (eg, MNF116 antibody), electron } \\
\text { microscopy, } A B C A 3 \text { mutation analysis }\end{array}$ & $\begin{array}{l}100 \% \text { (improved } \\
\text { survival when later } \\
\text { presentation) }\end{array}$ \\
\hline $\mathrm{SpB}^{16}$ & Newborn & $\begin{array}{l}\text { Interstitial thickening with } \\
\text { prominent type II } \\
\text { pneumocytes, PAP }\end{array}$ & CPI, NSIP, DIP & $\begin{array}{l}\text { Broad spectrum anticytokeratin IHC } \\
\text { (eg, MNF116 antibody), anti-SpB IHC, } \\
\text { electron microscopy, SpB mutation } \\
\text { analysis }\end{array}$ & $100 \%$ \\
\hline $\mathrm{SpC}^{4}$ & 2-22 months & $\begin{array}{l}\text { Interstitial thickening with } \\
\text { prominent type II } \\
\text { pneumocytes, DIP, CPI. }\end{array}$ & NSIP, PAP & $\begin{array}{l}\text { Broad spectrum anticytokeratin IHC } \\
\text { (eg, MNF116 antibody), SpC }\end{array}$ & 0 \\
\hline
\end{tabular}

AGA, alveolar growth abnormality; CPI, chronic pneumonitis of infancy; DIP, desquamative interstitial pneumonia; DLD, diffuse lung disease; EVG, Elastic Van Gieson; IHC, immunohistochemistry; NSIP, non-specific interstitial pneumonitis; PAP, pulmonary alveolar proteinosis; PAS, periodic acid Schiff; SpB, surfactant protein B; SpC, surfactant protein C; SMA, smooth muscle actin.

significant alveolar structural simplification with fibrosis. CNLD is now more common in premature neonates than HMD/BPD due to the advent of prenatal steroid administration, surfactant replacement therapy and more refined ventilatory support. Therefore, $\mathrm{HMD} / \mathrm{BPD}$ is now rarely seen in premature neonates.
Figure 4 Acinar dysplasia.

(A) Thoracic contents from a 24-week fetal death in utero showing bilateral, extremely small, granular lungs. The lungs are scarcely bigger than the atrial appendages. (B) Microscopic appearance of acinar dysplasia with airway development limited to bronchial and bronchiolar structures only, with no distal airways development. This imparts a distinctly lobular appearance, reminiscent of the pseudoglandular stage of fetal lung development. These lobules are surrounded by abundant loose mesenchyme.
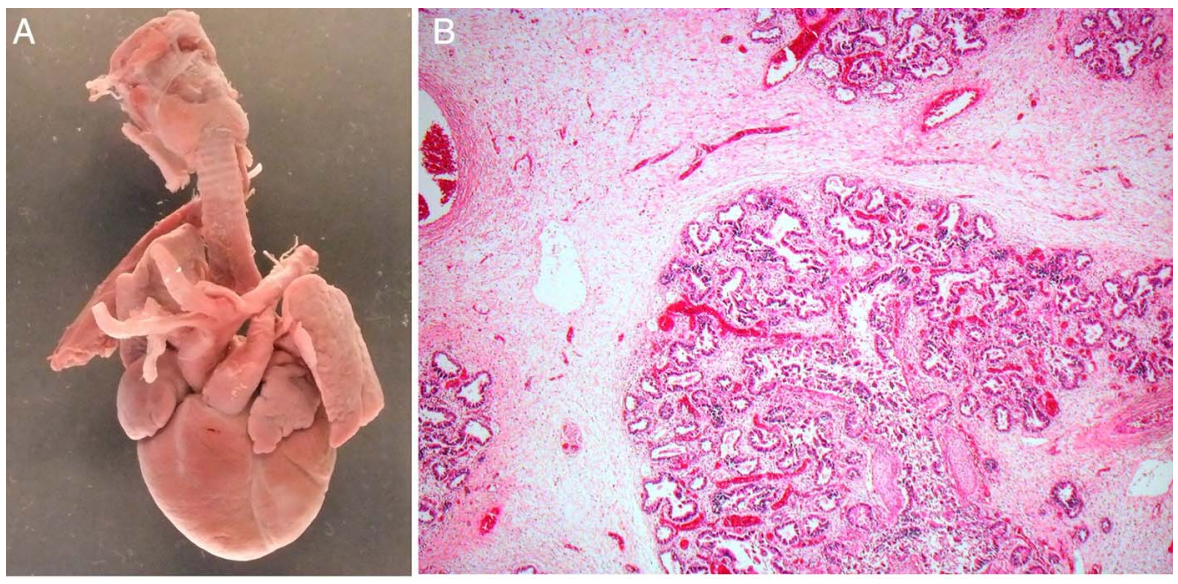


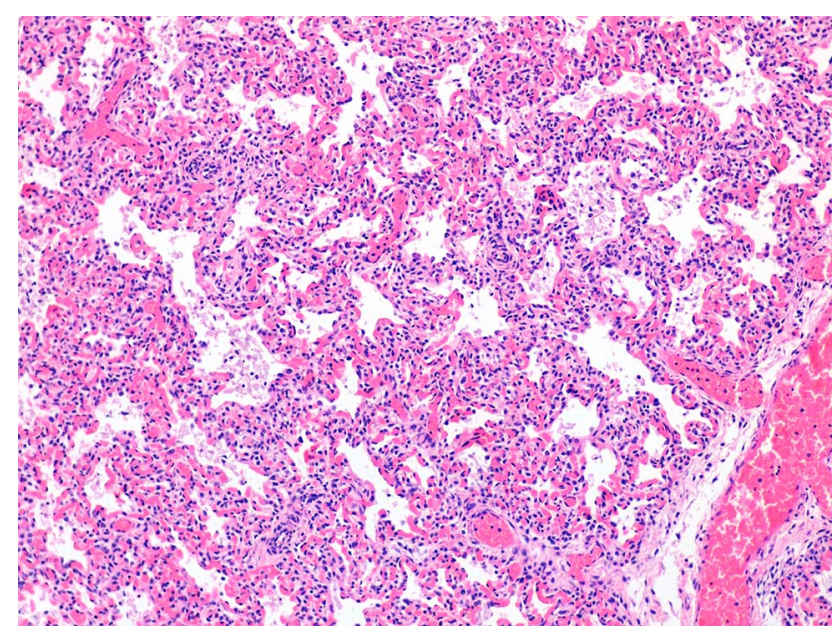

Figure 5 Congenital alveolar dysplasia in a 2-month-old infant, born at 37 weeks gestation. The lung abnormality is diffuse and shows development reminiscent of the late canalicular/early saccular stage of fetal lung maturation. There are angulated distal airspaces, and mesenchymal crests are present. Many of the epithelial cells lining the airspaces are columnar. The neonate was ventilated and subsequently died. The abnormality must be diffusely present throughout the lungs to make the diagnosis.

Similar alveolar simplification may occur in term infants if there is pulmonary hypoplasia (eg, due to oligohydramnios, congenital diaphragmatic hernia, neuromuscular abnormalities and others), in neonates with congenital heart disease or in neonates with chromosomal abnormalities, particularly Trisomy 21 . In the latter condition, the alveolar simplification is characteristically subpleural. One study showed that prematurity or congenital heart disease was highly predictive of AGA as the primary histological pattern of DLD. ${ }^{4}$ AGA can also occur in term infants who develop early postnatal infections which inhibits appropriate postnatal lung development. AGA has also been described in otherwise normal term neonates. $^{2}$ A small proportion of these are infants of diabetic mothers. In other cases, it is presumed that undetected fetal hypoxia prevented normal alveolar growth. ${ }^{2}$ More recently, both AGA and extensive emphysematous change have been described in infants with TTF-1 (NKX2.1) deficiency, as part of the triad of cerebral dysgenesis, thyroidal dysfunction and severe pulmonary insufficiency which characterise the phenotype of this genetic disorder. ${ }^{10}$

The outcome of AGA is variable depending on the underlying aetiology, the severity of the alveolar simplification and the presence of pulmonary hypertension. In one cohort, the overall mortality was $34 \%{ }^{4}$

\section{Non-inflammatory interstitial thickening}

Interstitial thickening can be the main histological pattern of a number of disparate causes of DLD and also is commonly admixed with other disease patterns. The cause of the interstitial thickening should be carefully noted (eg, due to an inflammatory infiltrate, oedema and other causes) to facilitate assessing the cause of the lung pathology.

\section{Pulmonary interstitial glycogenosis}

The most common cause of a non-inflammatory, cellular interstitial infiltrate is PIG, which occurs in very young infants, usually $<2$ months of age and rarely in infants $>6$ months of age. ${ }^{2} 4$ The characteristic feature is diffuse (more rarely focal) expansion of the interstitium due to vimentin-positive, mesenchymal, oval to spindle cells with cytoplasmic clearing (figure 6). Somewhat confusingly, glycogen is not demonstrated following periodic acid Schiff stain on light microscopy in the majority of cases and hence lack of glycogen identified on light microscopy should not preclude this diagnosis. ${ }^{2}$ Perhaps for this reason PIG is said to be underdiagnosed. ${ }^{9}$ Glycogen droplets are more readily identified by electron microscopy. ${ }^{11}$ Interstitial fibrosis and an inflammatory infiltrate are minor, if present, in PIG and type II pneumocyte hyperplasia is not a feature of this condition.

PIG is commonly seen on a background of AGA, particularly when due to prematurity, and PIG has been noted to occur in more than $50 \%$ of cases of AGA presenting in infants below 6 months of age. ${ }^{2}$ PIG has also been documented in conjunction with $\mathrm{CAD}, \mathrm{ACD}$, persistent pulmonary hypertension and congenital lobar emphysema. ${ }^{3}$ The aetiology of PIG is poorly understood, but it may represent a persistence of embryological mesenchymal cells. ${ }^{3}$ In one series, there were no deaths due to PIG and the prognosis is generally good, depending on the severity of any associated lung conditions. ${ }^{4} 12$

\section{ACD and misalignment of pulmonary veins}

The prominent low-power histological pattern of this complex developmental disease of pulmonary vasculature is interstitial thickening (figure 7). The alveolar capillaries are abnormally placed and central within the thickened alveolar septa and are not closely opposed to the lining pneumocytes. These abnormally placed capillaries can be advantageously visualised with antibodies to endothelial antigens such as CD31 (figure 7B). There is accompanying misalignment of pulmonary veins, which
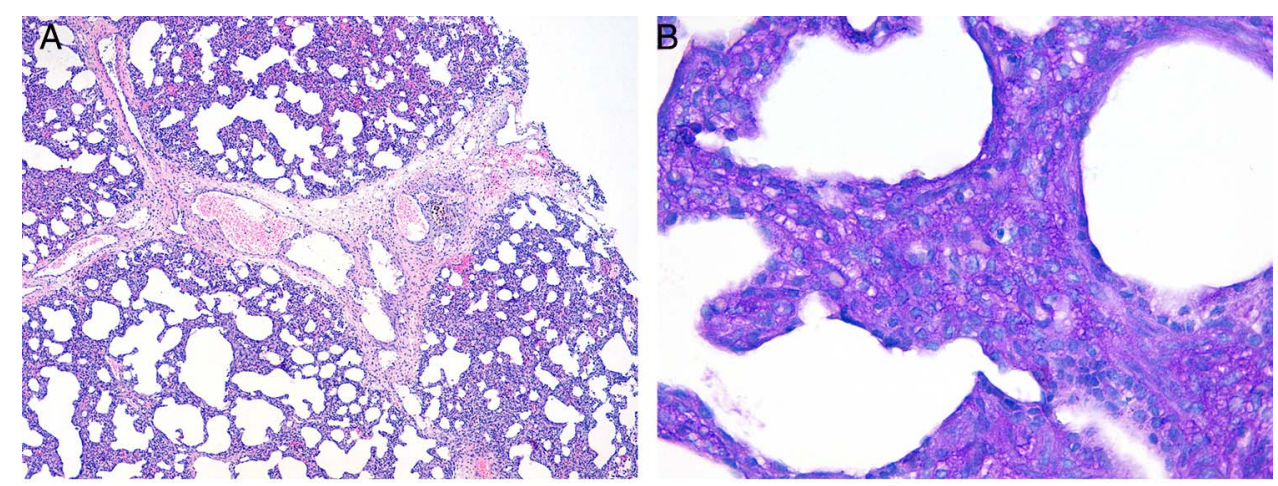

Figure 6 Alveolar growth abnormality with pulmonary interstitial glycogenosis. (A) There is diffuse enlargement and simplification of alveolar spaces. The interstitium is thickened. In addition, there is oedema of the interlobular septum, with distension of the veins and lymphatics and focal deposition of haemosiderin. (B) Thick alveolar septae due to oval and spindle cells with cytoplasmic glycogen demonstrated by periodic acid Schiff. There is no significant interstitial inflammatory cell infiltrate. 


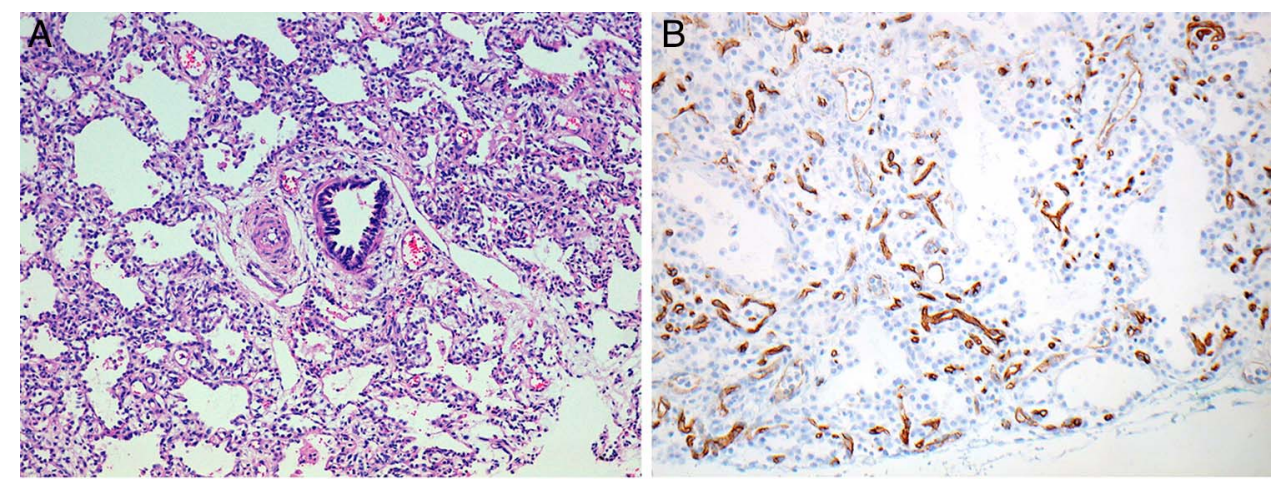

Figure 7 Alveolar capillary dysplasia with misalignment of the pulmonary veins. (A) There is characteristic interstitial thickening with broadened alveolar septa. Capillaries, where they can be identified, are not situated immediately subjacent to alveolar epithelium, but are in the middle of the septa at a distance from the airspaces. There is muscular medial hypertrophy of a small muscular pulmonary artery, indicating pulmonary arterial hypertension. Within the same fibrous sheath as the artery and bronchiole, there are vascular structures (4 o'clock and 11 o'clock) that have thin, muscular walls and contain blood in their lumina. These are misaligned pulmonary veins (elsewhere in the biopsy specimen no veins could be identified in the interlobular septa). Several small dilated lymphatic vessels are also present. (B) CD31 immunohistochemistry highlights the abnormally placed capillaries that lie centrally within the alveolar septa.

run within the bronchovascular bundles, alongside the pulmonary arteries (figure $7 \mathrm{~A}$ ), although larger pulmonary veins occasionally may be normally placed within the inter-lobular septa. ${ }^{9}$ Due to this abnormal venous drainage, the capillaries within the alveolar septa are often congested and there are changes of pulmonary arterial hyperplasia, which are seen as medial hypertrophy of small muscular pulmonary arteries and muscularisation of the arterioles. Lymphangiectasia is usually prominent, and ACD may be associated with AGA and PIG. Importantly, neither type II pneumocyte hyperplasia nor inflammation is present in this disease and there is no significant debris or cellular material within the alveolar spaces.

The clinical history is important when considering a diagnosis of ACD. These neonates are usually born at term and develop early symptoms of severe pulmonary hypertensive disease, hypoxia and progressive respiratory failure which begin a few hours after birth. Most biopsies for this condition are therefore taken within the first month of life. The neonate often has other congenital abnormalities, particularly including the cardiac, gastrointestinal or renal systems. ACD has been associated with heterozygous FOXF1 gene mutations. These mutations are usually sporadic, although rare cases appear maternally inherited due to imprinting of the paternal allele. ${ }^{13}$ ACD is fatal in early infancy.

\section{Interstitial thickening with a mild inflammatory interstitial infiltrate and type II pneumocyte hyperplasia \\ Surfactant protein deficiencies}

In infancy, interstitial thickening due to a mild interstitial inflammatory infiltrate and oedema is often accompanied by prominent, uniform and diffuse type II pneumocyte hyperplasia (figure 8). This histological pattern is known as chronic pneumonitis of infancy (CPI) and is most commonly associated with congenital surfactant protein deficiency, particularly deficiency of surfactant protein $\mathrm{C}(\mathrm{SpC})$, which has autosomal-dominant inheritance. Type II pneumocytes are readily demonstrated by broad-spectrum anticytokeratin antibodies, such as MNF116. This histological appearance is different to that of the subacute/fibroproliferative phase of HMD, when type II pneumocytes may also be prominent, since in HMD evidence of severe acute lung damage is present, including resolving hyaline membranes. Nonetheless, these two conditions may coexist.

In addition to the interstitial inflammatory infiltrate and type II pneumocyte hyperplasia characteristic of surfactant protein deficiency, two further features may also be observed in differing proportion, that is, pulmonary alveolar proteinosis (PAP) and numerous macrophages within the alveolar spaces, that is, desquamative interstitial pneumonia (DIP). Depending on the prominence of these features, it is possible to suggest the specific genetic aberration that has led to the surfactant protein deficiency.

PAP is diagnosed when eosinophilic proteinaceous debris is prominent within the alveolar spaces (figures 9 and 10). The histological appearance of PAP occurring in infants and adults is similar. However, their aetiology is different. PAP in infancy is invariably combined with interstitial thickening and type II pneumocyte hyperplasia and is most likely due to recessively inherited mutations in the surfactant protein $\mathrm{B}(S p B)$ gene or ATP-binding cassette transporter A3 (ABCA3) gene. Further,
Figure 8 Chronic pneumonitis of infancy with known surfactant protein C deficiency. (A) There is diffuse interstitial thickening and type II pneumocyte hyperplasia without significant alveolar proteinosis or desquamative pneumonia. (B) At high power, type II pneumocyte hyperplasia is obvious and the thickened interstitium contains scattered chronic inflammatory cells.

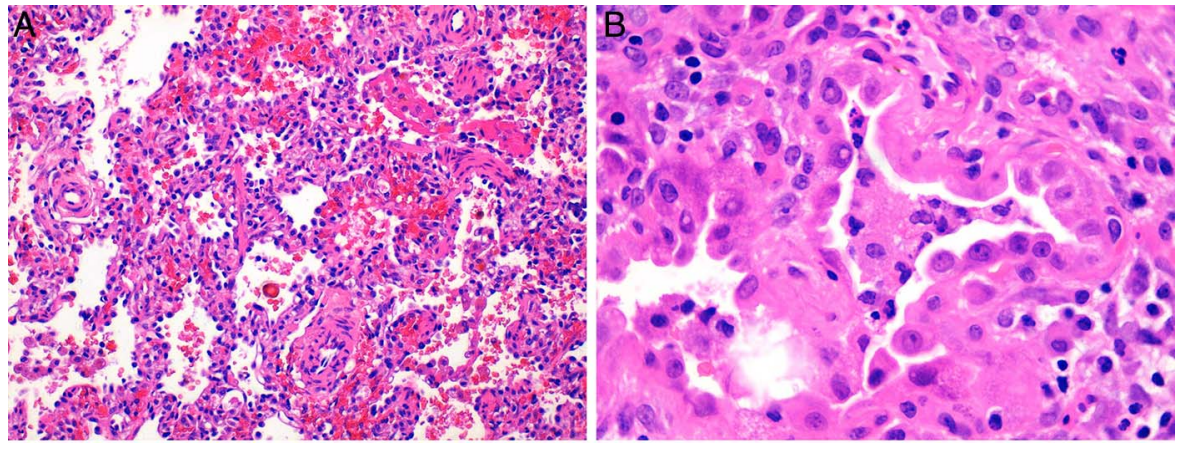




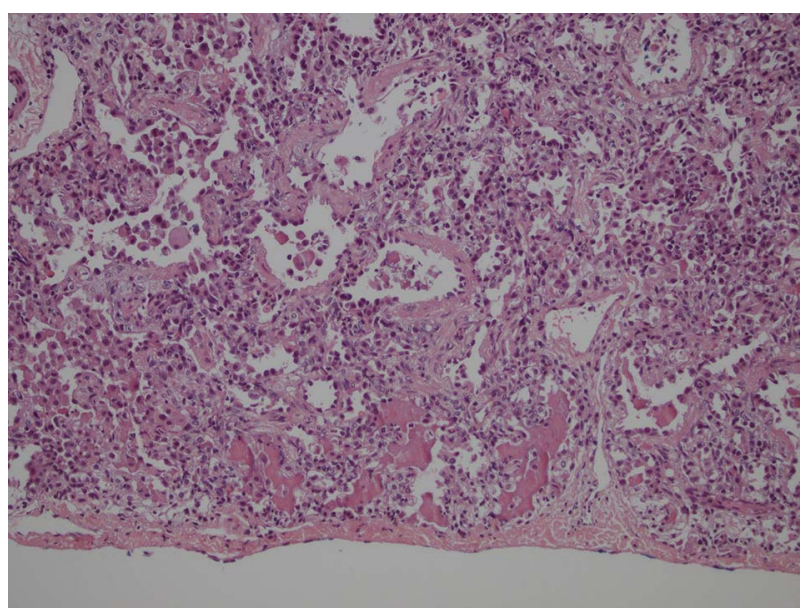

Figure 9 ABAC3 deficiency. Interstitial thickening with florid type II pneumocyte hyperplasia and pulmonary alveolar proteinosis due to genetically proven $A B C A 3$ deficiency. The eosinophilic debris within the alveolar spaces has a characteristic 'glassy' appearance. There are abundant intra-alveolar macrophages. There is also hyperplasia of smooth muscle in the interstitium.

ABCA3 deficiency is said to confer characteristic 'glassy' intra-alveolar proteinaceous deposits, which can be useful to direct genetic investigations (figure 9). The alveolar protein in $\mathrm{SpB}$ deficiency tends to be more granular. Anti-SpB antibodies can be used to demonstrate absent $\mathrm{SpB}$ expression within the pneumocyte population and intra-alveolar debris in $S p B$ mutation (figure 10). $\mathrm{SpB}$ and $\mathrm{ABCA} 3$ deficiency can also be inferred by their characteristic ultrastructural appearance; deficient mature lamellar bodies with SpB deficiency compared with absent mature lamellar bodies and the presence of distinctive electron-dense bodies within small lamellar bodies ('fried egg' appearance) in ABCA3 deficiency. ${ }^{14} 15$

As with PAP, DIP-like changes in infant lungs are usually a manifestation of surfactant protein deficiency, including ABCA3 deficiency and SpC deficiency. The characteristic feature is the presence of numerous foamy macrophages within the alveolar spaces, sometimes containing cholesterol clefts, together with interstitial thickening, and type II pneumocyte hyperplasia. There may be overlap with PAP, particularly with ABCA3 deficiency and CPI with SpC deficiency. No characteristic ultrastructural findings have been described with $\mathrm{SpC}$ deficiency.

$\mathrm{SpB}$ deficiency presents in newborns and is invariably fatal. ${ }^{16}$ ABCA3 deficiency presenting at a young age (0.2-3 months) is also a fatal disease. ${ }^{4}$ However, there is accumulating evidence that ABCA3 deficiency may present in later childhood as nonspecific interstitial pneumonitis with less severe lung disease and an improved outcome. ${ }^{17} 18$ In contrast with SpB deficiency and $\mathrm{ABCA} 3$ deficiency presenting in infancy, $\mathrm{SpC}$ deficiency has a relatively good outcome.

Miscellaneous causes of interstitial thickening and PAP

Similar PAP changes as that seen with surfactant protein deficiencies can be seen in older infants as a response to infection, particularly viral infection. In this clinical setting, viral inclusions are occasionally visible and appropriate molecular or culture investigations for viral infection should be performed. PAP has also been described in infancy in the absence of a surfactant protein deficiency in conditions such as malignancy, immunodeficiency and in the rare autosomal-recessive condition: lysinuric protein intolerance. ${ }^{19}$

\section{Interstitial thickening with prominent interstitial inflammatory cells and fibrosis}

A prominence of chronic inflammatory cells as a cause of interstitial thickening is relatively rare in this age group and is termed non-specific interstitial pneumonia (NSIP). The inflammatory infiltrate is usually composed of lymphocytes and plasma cells and is characteristically temporally uniform across the biopsy. Cellular expansion of the interstitium is also the main histological feature of PIG and PIG is much more common than NSIP in this age group. However, PIG should not be diagnosed if the interstitial cells are inflammatory. There may be type II pneumocyte hyperplasia in NSIP and minor interstitial macrophages, but these findings are not as strikingly diffuse as in CPI, DIP and PAP. Fibrosis may be present, but is patchy and mild. Organising pneumonia also can be seen. As its appellation implies, NSIP is non-specific as to aetiology and can remain idiopathic, despite extensive investigation. While older children with surfactant protein deficiency, including $\mathrm{SpC}$ and ABCA3 deficiency, can show NSIP on biopsy, NSIP is not the usual presentation of surfactant protein deficiency in children $<2$ years of age. Other causes are not specific to this age group and include infections and hypersensitivity pneumonitis.

\section{Pulmonary hypertensive disease}

Histological changes of pulmonary hypertension are relatively common in lung biopsies in infants, but are usually secondary to other disease. Nonetheless, the hypertensive changes may be the most striking histological feature identified within a biopsy.
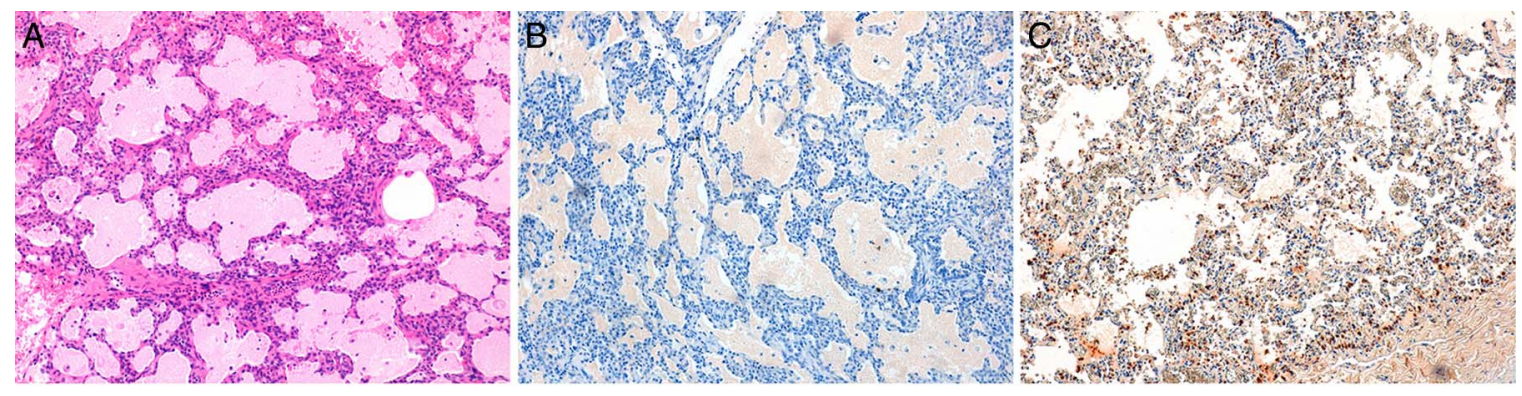

Figure 10 Surfactant protein B deficiency. (A) Interstitial thickening, and a striking quantity of granular, proteinaceous debris within alveolar spaces. Macrophages are not especially prominent, and there is little type II pneumocyte hyperplasia evident in this field. (B) Immunohistochemical staining with antibody to surfactant protein $B$ is negative. Type 2 pneumocyte hyperplasia is more evident than in the $H \& E$ section. (C) Immunohistochemical staining with antibody to surfactant protein B in control lung tissue. Staining of surfactant protein B is present in type II pneumocytes lining the alveolar walls, and to a lesser extent, in the alveolar spaces. 


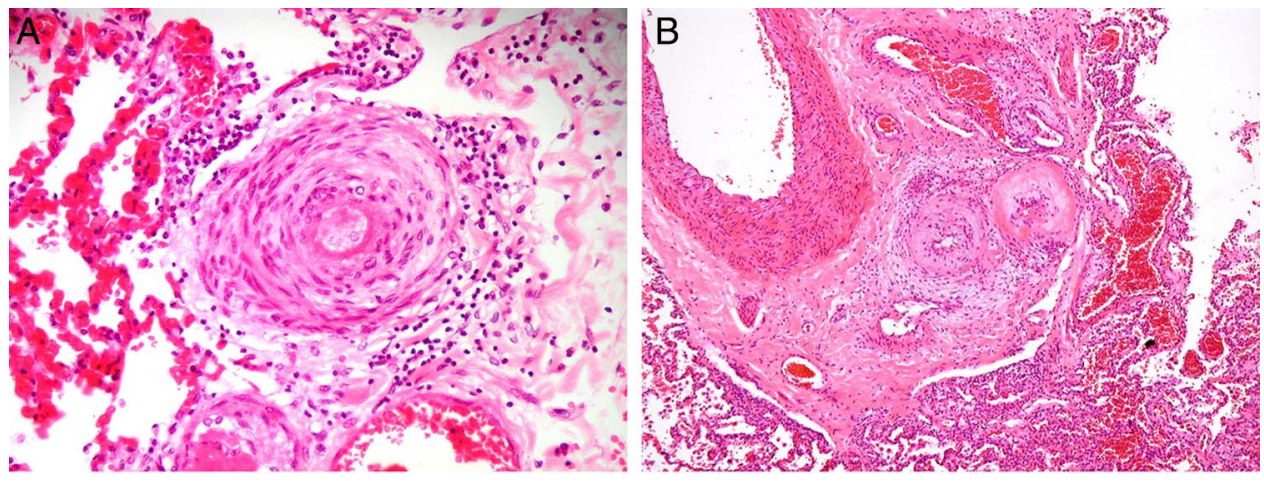

Figure 11 Pulmonary arterial hypertension. (A) Cellular intimal thickening of small muscular pulmonary arteries. (B) Plexiform lesion. The parent artery is present to the left of the field and shows only mild intimal thickening. Several branches are present in its adventitial coat, and these show severe concentric, fibrous and myxoid intimal thickening with deposition of fibrinoid. Within the lumen of one vessel (3 o'clock), there is cellular proliferation with the formation of slit-like vascular lumina, creating a plexiform lesion. Surrounding this there are thin-walled dilated vessels, the whole forming a complex vascular lesion.

In order to determine the cause of the hypertensive change, clinical history is paramount, together with identification of any other lung histopathology. Pulmonary hypertensive changes can primarily affect the arterial vasculature or affect both the arterial and venous systems. The causes are usually distinct.

In all biopsies where vessel abnormality is considered, an EVG histochemical stain is essential. CD34 or CD31 immunohistochemistry (IHC) is also useful to highlight the entire vascular component of the biopsy, and smooth muscle actin IHC will highlight abnormally muscularised vessels.

\section{Pulmonary arterial hypertension}

Pulmonary arterial hypertension is seen as medial hyperplasia of small muscular pulmonary arteries and muscularisation of arterioles. The more severe forms show cellular and fibrous intimal proliferation (figure 11A) and there may be deposition of fibrinoid, foam cells or plexiform lesions in the most severe cases (figure 11B). Additionally, elastic pulmonary arteries may show atheromatous intimal plaques, although these vessels are rarely seen on lung biopsy.

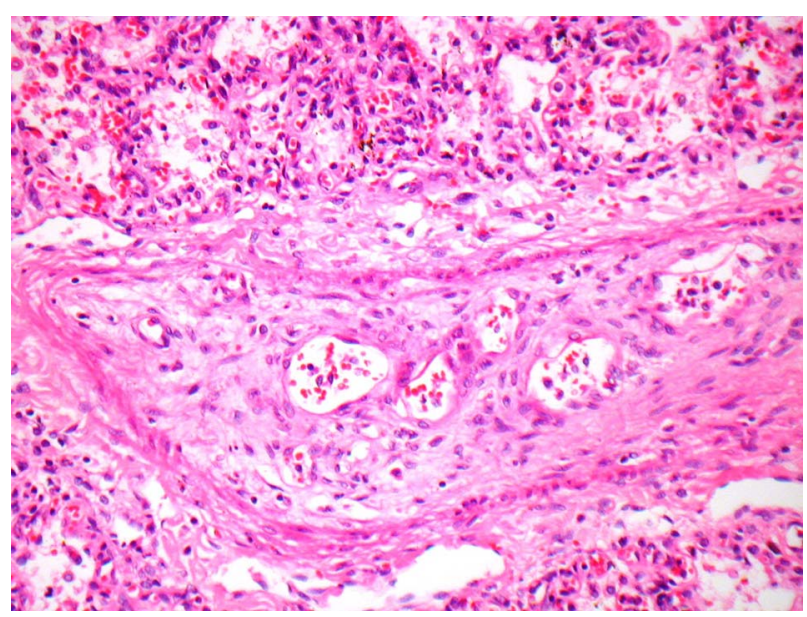

Figure 12 Pulmonary veno-occlusive disease. A large septal vein is shown in semi-longitudinal section. The original muscular media is evident as a thin cuff around the vessel, and the lumen is occluded by myxoid and fibrous and cellular intimal proliferation. There is a residual narrow and tortuous lumen. There is surrounding severe alveolar capillary congestion. There is also lymphatic dilatation.
Pulmonary arterial hypertension (without significant venous pathology) most commonly occurs with congenital heart disease with significant, uncorrected left-to-right shunts (eg, truncus arteriosus, transposition of great arteries, complete atrial ventricular septal defects). However, lung biopsy is now rarely performed in this clinical setting. Infrequently, pulmonary hypertensive disease may be idiopathic, either sporadic or familial. ${ }^{20}$

\section{Pulmonary venous hypertension}

Pulmonary venous hypertension will occur with any disease that increases pulmonary venous pressure due to left-sided obstruction. Histologically there is muscularisation of pulmonary veins together with variable intimal proliferation. There is congestion of alveolar capillaries, intra-alveolar haemosiderin-laden macrophages and occasionally calcification or ossification of the pulmonary interstitium. In pulmonary veno-occlusive disease, the septal veins show prominent intimal cellular proliferation, which can

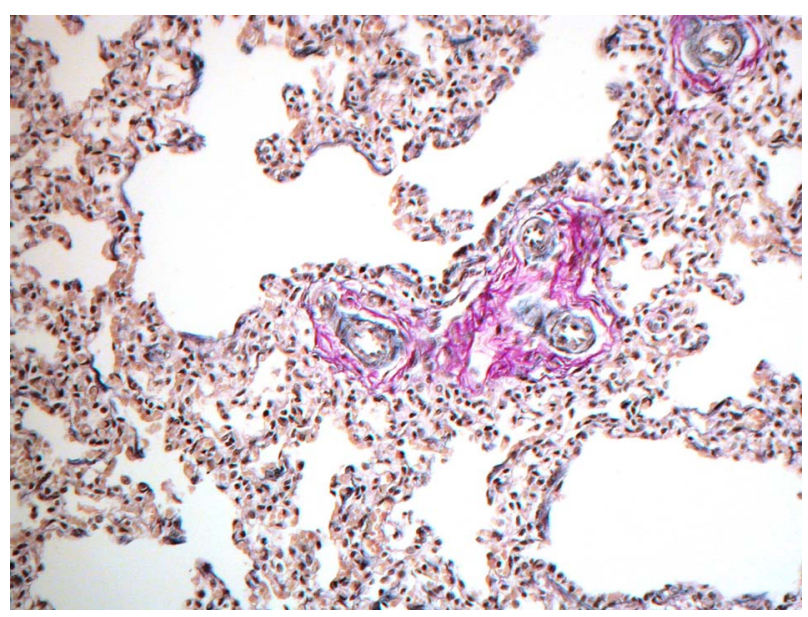

Figure 13 Persistent pulmonary hypertension of the newborn. The lung is immature (thickened interstitium with double capillary loops). There are multiple profiles of an artery accompanying a respiratory bronchiole. The artery is thick-walled and muscular and is contractedthe endothelial cells are crowded together and pushed into the lumen in a hobnail pattern (Elastic Van Gieson). After birth, under the influence of increasing oxygen tension these arteries should normally dilate. In persistent pulmonary hypertension of the newborn, the majority of intra-acinar arteries in the lung have this constricted appearance. 


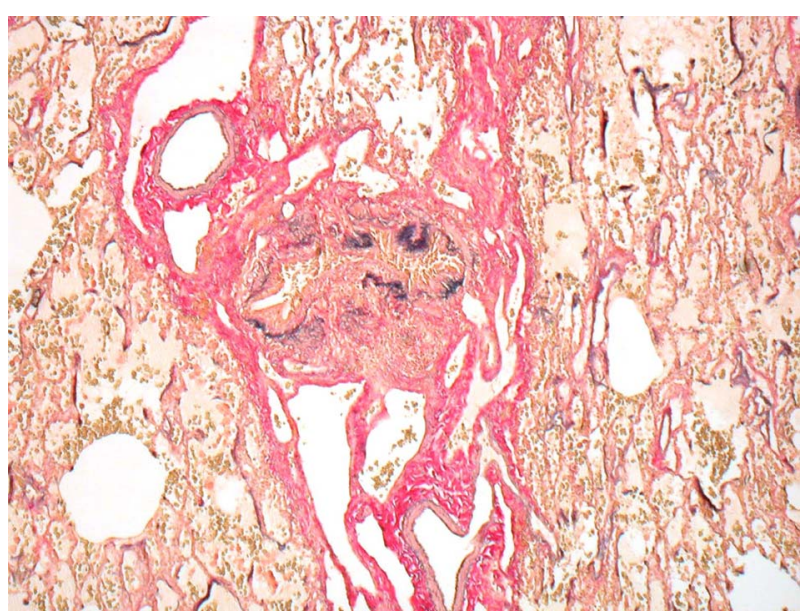

Figure 14 Lymphangiectasia. A bronchovascular bundle that shows large numbers of greatly dilated lymphatic vessels ramifying in the collagen surrounding the bronchiole and muscular pulmonary artery (Elastic Van Gieson).

lead to venous occlusion (figure 12). The biopsy will also demonstrate a strikingly patchy distribution of capillary congestion. Pulmonary venous hypertension is seen with obstructed pulmonary venous connections, pulmonary vein stenosis, severe left atrioventricular valve regurgitation and pulmonary veno-occlusive disease. Similar changes can also be seen in chronic heart failure.

Persistent pulmonary hypertension of the newborn

Neonates may present with severe hypoxia due to persistent pulmonary hypertension. This condition usually is adequately diagnosed without lung biopsy. However, it is characterised histopathologically by abnormal, peripherally placed thickwalled arteries that may be contracted (figure 13). The cause of failure of the usual reduction of pulmonary vascular resistance postnatally is multifactorial, but most commonly seen with meconium aspiration syndrome. ${ }^{21}$

\section{Lymphangiectasia}

Lymphangiectasia is seen as dilated lymphatic channels in the bronchovascular bundle, inter-lobular septa and pleura (figure 14). The lymphatics can be specifically identified with the antibody D2-40, a marker of lymphatic endothelium. There can be accompanying chylothorax, leading to pulmonary hypoplasia. Lymphangiectasia is common as a secondary phenomenon with chronic heart failure, venous obstruction, chronic lymphatic obstruction and ACD. It may also be seen with genetic and congenital disorders such as Noonan's, Down, Ullrich-Turner and Ehlers-Danlos syndromes. ${ }^{22}$ However, rarely, congenital pulmonary lymphangiectasia is identified, indicating its development in the absence of other causes. Congenital pulmonary lymphangiectasia presents in newborns and is uniformly fatal. ${ }^{22}$

\section{The normal-appearing lung biopsy}

Occasionally, infants who present with persistent tachypnoea and hypoxia indicative of DLD have a biopsy that appears relatively normal on routine $\mathrm{H} \& \mathrm{E}$ staining or may contain non-specific minor changes such as a mild increase of airway-associated lymphoid tissue and mild hyperplasia of airway smooth muscle. A proportion of these cases will have neuroendocrine cell hyperplasia of infancy (NCHI), a relatively recently described entity. The diagnosis can be made on biopsy due to increased neuroendocrine cell

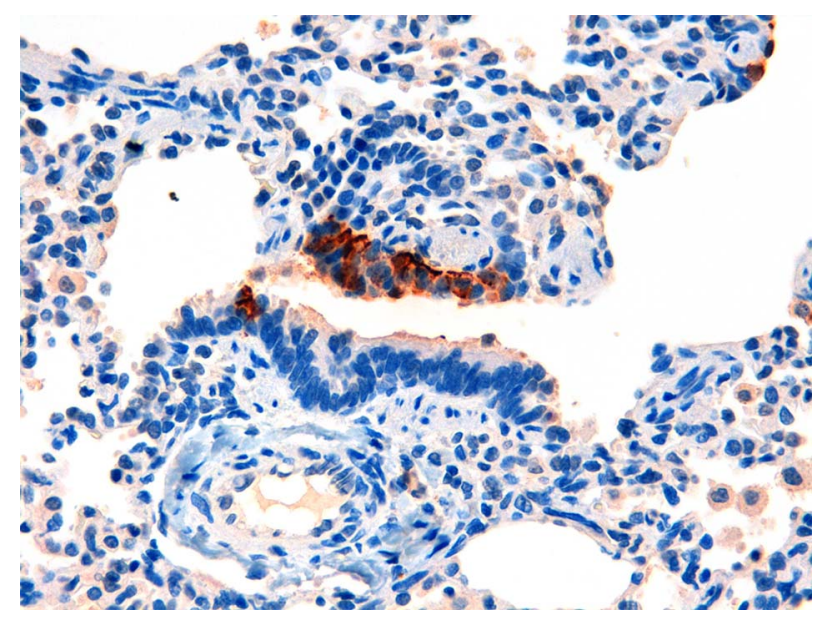

Figure 15 Neuroendocrine cell hyperplasia of infancy, showing increased numbers of neuroendocrine cells in a small airway, identified by antibombesin immunohistochemistry.

numbers in small airways identified by IHC with antibodies to bombesin (figure 15). Infants diagnosed with this condition are usually born at term and may not present until 1 year of age. ${ }^{4} 1223$ Symptoms may be precipitated by lung infection. This condition is said to have characteristic imaging, that is, central and right middle lobe and lingula ground glass densities seen on high-resolution $\mathrm{CT}^{24} \mathrm{NCHI}$ was found in $3.2 \%$ of biopsies taken for symptoms of interstitial lung disease in childhood in one retrospective institutional study. ${ }^{3}$ The outcome is generally good, with no reported cases of respiratory failure or death due to this condition.

Not all normal-appearing lung biopsies in symptomatic infants warrant the diagnosis of NCHI. In one retrospective, institute-based study of biopsies taken for symptoms of DLD presenting in children at $<2$ years of age, an equal proportion of NCHI, normal and non-diagnostic diagnoses were issued (3.2\% in each category). ${ }^{3}$

\section{DLD not specific to infancy}

As seen in box 1 , infants may present with DLD not specific to this young age group. Infection is commonly seen and has been documented to constitute $17 \%$ and $18 \%$ of DLD of infancy in two separate studies. ${ }^{4} 24$ Other relatively common DLDs in this age group are immune-mediated or collagen vascular diseases affecting the lungs, aspiration syndromes and hypersensitivity pneumonitis. The histological appearance of these conditions does not vary significantly from that seen in older children and adults. Of note, usual interstitial pneumonia, characterised as temporally heterogeneous fibrosis, is not seen in infants.

\section{CONCLUSION}

DLD of infancy has many aetiologies. Some diseases are specific to this young age group, while others are not. Recently published series of DLD of infancy, taken from the archives of specialist centres, indicate that many cases are referred for expert opinion from more generalist pathologists. We present an algorithmic approach to the diagnosis of DLD of infancy which may be of use to the non-specialist pathologist. As with any suggested algorithmic approach to diagnosis, practical common sense is necessary when faced with paediatric lung biopsies and expedient referral to a specialised centre, for either primary or confirmatory diagnosis, may often be required. In all cases, ultimate diagnosis is necessarily based on a multidisciplinary approach, including clinical, radiological and pathological input. 
Acknowledgements We wish to thank Ms Vicki Adams, Mater Education Centre, Mater Health Services for her technical assistance.

Contributors JEA devised the algorithm and drafted the manuscript. MA and WM contributed to the manuscript and supplied the majority of the figures and figure legends.

\section{Competing interests None.}

Provenance and peer review Not commissioned; externally peer reviewed.

Open Access This is an Open Access article distributed in accordance with the Creative Commons Attribution Non Commercial (CC BY-NC 4.0) license, which permits others to distribute, remix, adapt, build upon this work non-commercially, and license their derivative works on different terms, provided the original work is properly cited and the use is non-commercial. See: http://creativecommons.org/ licenses/by-nc/4.0/

\section{REFERENCES}

1 Kurland G, Deterding RR, Hagood JS, et al. An official American Thoracic Society clinical practice guideline: classification, evaluation, and management of childhood interstitial lung disease in infancy. Am J Respir Crit Care Med 2013;188:376-94.

2 Langston C, Dishop MK. Diffuse lung disease in infancy: a proposed classification applied to 259 diagnostic biopsies. Pediatr Dev Pathol 2009;12:421-37.

3 Rice A, Tran-Dang MA, Bush A, et al. Diffuse lung disease in infancy and childhood: expanding the chILD classification. Histopathology 2013;63:743-55.

4 Deutsch GH, Young LR, Deterding RR, et al. Diffuse lung disease in young children: application of a novel classification scheme. Am J Respir Crit Care Med 2007;176:1120-8.

5 Sebire NJ, Malone M, Ashworth M, et al. Diagnostic pediatric surgical pathology. New York: Churchill Livingstone Elsevier, 2010; Chapter 12, Respiratory Pathology.

6 Kreiger PA. Chapter 2, Lung. In: Color atlas of fetal and neonatal histology. Ernst LM, Ruchelli eds. New York: Springer, 2011;21-35.

7 Langston C, Patterson K, Dishop MK, et al. A protocol for the handling of tissue obtained by operative lung biopsy: recommendations of the chILD pathology co-operative group. Pediatr Dev Pathol 2006;9:173-80.

8 Stocker JT, McGill CL, Orsini EN. Congenital pulmonary airway malformation-a new name for and expanded calssification of congenital cystic adenomatoid malforamtion of the lung. Histopathology 2003;41:424-31.

9 Dishop MK. Paediatric interstitial lung disease: classification and definitions. Paediatr Respir Rev 2011;12:230-7.
10 Galambos C, Levy H, Cannon CL, et al. Pulmonary pathology in thyroid transcription factor-1 deficiency syndrome. Am J Respir Crit Care Med 2010;182:549-54.

11 Canakis AM, Cutz E, Manson D, et al. Pulmonary interstitial glycogenosis: a new variant of neonatal interstitial lung disease. Am J Respir Crit Care Med 2002;165:1557-65.

12 Deutsch GH, Young LR. Pulmonary interstitial glycogenosis: words of caution. Pediatr Radiol 2010;40:1471-5.

13 Sen P, Yang Y, Navarro C, et al. Novel FOXF1 mutations in sporadic and familial cases of alveolar capillary dysplasia with misaligned pulmonary veins imply a role for its DNA binding domain. Hum Mutat 2013;34:801-11.

14 Edwards V, Cutz E, Viero S, et al. Ultrastructure of lamellar bodies in congenital surfactant deficiency. Ultrastruct Pathol 2005;29:503-9.

15 Tryka AF, Wert SE, Mazursky JE, et al. Absence of lamellar bodies with accumulation of dense bodies characterizes a novel form of congenital surfactant defect. Pediatr Dev Pathol 2000;3:335-45.

16 Cazzato S, di Palmo E, Ragazzo V, et al. Interstitial lung disease in children. Early Hum Dev 2013;89(Suppl 3):S39-43.

17 Bullard JE, Wert SE, Whitsett JA, et al. ABCA3 mutations associated with pediatric interstitial lung disease. Am J Respir Crit Care Med 2005;172: 1026-31.

18 Doan ML, Guillerman RP, Dishop MK, et al. Clinical, radiological and pathological features of ABCA3 mutations in children. Thorax 2008:63:366-73.

19 Parto K, Kallajoki M, Aho H, et al. Pulmonary alveolar proteinosis and glomerulonephritis in lysinuric protein intolerance: case reports and autopsy findings of four pediatric patients. Hum Pathol 1994;25:400-7.

20 Ma L, Chung WK. The genetic basis of pulmonary arterial hypertension. Hum Genet 2014:133:471-9.

21 Puthiyachirakkal M, Mhanna MJ. Pathophysiology, management, and outcome of persistent pulmonary hypertension of the newborn: a clinical review. Front Pediatr 2013;1:23

22 Faul JL, Berry GJ, Colby TV, et al. Thoracic lymphangiomas, lymphangiectasis, lymphangiomatosis, and lymphatic dysplasia syndrome. Am J Respir Crit Care Med 2000;161:1037-46.

23 Deterding RR, Pye C, Fan LL, et al. Persistent tachypnea of infancy is associated with neuroendocrine cell hyperplasia. Pediatr Pulmonol 2005;40:157-65.

24 Soares JJ, Deutsch GH, Moore PE, et al. Childhood interstitial lung diseases: an 18-year retrospective analysis. Pediatrics 2013;132:684-91. 